\title{
O direito através dos processos: notas sobre as práticas jurídicas no Supremo Tribunal Federal
}

\section{Andressa Lewandowski}

\section{(2) OpenEdition \\ 1 Journals}

Edição electrónica

URL: http://journals.openedition.org/aa/2453

DOI: 10.4000/aa.2453

ISSN: 2357-738X

Editora

Programa de Pós-Graduação em Antropologia Social (UnB)

\section{Edição impressa}

Data de publição: 1 dezembro 2016

Paginação: 157-178

ISSN: 0102-4302

\section{Refêrencia eletrónica}

Andressa Lewandowski, «O direito através dos processos: notas sobre as práticas jurídicas no

Supremo Tribunal Federal», Anuário Antropológico [Online], v.41 n.2 | 2016, posto online no dia 15 junho 2018, consultado o 28 abril 2021. URL: http://journals.openedition.org/aa/2453 ; DOI: https://doi.org/ 10.4000/aa. 2453

\section{(c) (i) (9)}

Anuário Antropológico is licensed under a Creative Commons Atribuição-Uso Não-Comercial-Proibição de realização de Obras Derivadas 4.0 International. 


\section{O direito através dos processos: notas sobre as práticas jurídicas no Supremo Tribunal Federal}

Andressa Lewandowski

UFSCAR

"Eu faço processo. $\mathrm{Na}$ verdade, eu faço processo, carrego processo, faço processo, carrego processo." Era isso que faziam grande parte dos meus interlocutores, e era dessa forma que descreviam suas atividades no tribunal. Fazer e carregar processos. Olhando agora, depois do trabalho de campo e da tese doutoral finalizada, percebo que todo o trabalho está no desenrolar dessa resposta. ${ }^{1}$ É isso que se faz no Supremo Tribunal Federal: faz-se processo, e fazendo processo se produz o direito e direitos.

Pensar o direito como prática tem sido o impulso de alguns dos trabalhos mais ou menos recentes envolvendo instituiçóes jurídicas (Barrera, 2009; Bevilacqua, 2010; Latour, 2009; Riles, 2011) e as instituiçôes estatais de modo geral. Se o Estado, como argumentam Latour e Riles, não é uma unidade, uma ideia, ou um ente abstrato que segue uma lógica única, então ele é uma prática que se "estrutura" a partir de elementos diversos, como documentos, técnicas, expertises - actantes, nos termos de Latour. $\mathrm{O}$ argumento parece entáo deslocar a análise de questóes como autoridade e autonomia (Latour, 2009), que partem de configuraçóes estruturais, campos, ou sistemas preexistentes (Pottage, 2012), para as qualidades legais produzidas com base na composição e nos fluxos de processos - "faço e carrego processo", diriam nossos interlocutores em campo.

A proposta aqui é rastrear esse movimento, esse fluxo de pessoas e coisas que circulam com e através dos autos processuais, ou através do direito, nos termos de Riles. Desse modo, é possível acompanhar as formas como se separam, classificam e transformam as questôes do mundo em objetos jurídicos com base em uma infinidade de papéis, carimbos, assinaturas e procedimentos. $\mathrm{O}$ direito, aqui entendido como modo de enunciaçáo, realiza-se justamente ali onde se reduz ao papel, àquilo que está na superfície de uma forma de conhecimento, que se torna meio (ferramenta) e, ao mesmo tempo, fim de uma lógica jurídica inscrita numa racionalidade procedimental que movimenta todas as operaçóes do tribunal, transformando fatos em autos, autos em votos, votos em decisôes e decisões em precedentes (Alexandre Nodari, 2014, comunicação pessoal). 
Como "emblemas" da burocracia moderna, Riles (2006) argumenta que os documentos ${ }^{2}$ articulam, mediam relações e permitem visualizar aquilo que é produzido através deles ou a partir deles. Desse modo, são objetos que instanciam, que mobilizam redes de ideias, pessoas e tecnologias (Riles, 2006) especialmente, como destaca Barrera (2008), em culturas de tradição civilista, como o caso brasileiro, em que as práticas judiciais se articulam, sobretudo, através de documentos escritos, como se "só existisse no mundo o que está corroborado no papel” (Peirano, 2009: 70). Na realidade, a relação aqui é menos metafórica: o objetivo de um processo é produzir um mundo próprio que se relaciona com as realidades fora dele. Um mundo que se faz "através" da lei, dos documentos e procedimentos, que descontextualiza (aqui no seu sentido positivo e negativo), reorganiza e cria objetos para o mundo. Como já afirmou Kant de Lima, “o 'mundo' do Direito não equivale ao mundo dos fatos sociais. Para 'entrar' no mundo do Direito os 'fatos' têm de ser submetidos a um tratamento lógico-formal” (1989: 71).

A existência das coisas no universo jurídico está relacionada à possibilidade de estas serem provadas e contraditadas, o que só acontece na medida em que estão nos autos processuais na forma de documentos disponíveis a todos os agentes de um processo. Desse modo, o que não está nos autos não pode nem deve estar no mundo de uma ação jurídica. Conforme Visman (2008), a dupla negação não está no mundo nem no processo, sumariza a operação performativa do direito na constituição da realidade e deixa claro que o direito e a realidade fora dele náo coincidem.

Em alguma medida, todo expediente legal destina-se a garantir a composição dos autos processuais. Pretendo, então, neste artigo reconstituir a circulação de um processo e compreender a economia processual que envolve pessoas, documentos e procedimentos no STF. Para que uma demanda judicializável chegue ao tribunal, última instância recursal disponível, é necessário um conjunto de documentos que compóem a denominada petição inicial. Uma petição inicial tem como objetivo provocar a jurisdição que é exercida pelo STF, ainda que essa jurisdição tenha se transformado ao longo do tempo, náo sendo consensuais os limites em que podem atuar os ministros e o tribunal.

Quando entregue, uma petição é registrada no sistema eletrônico do STF (E-JUD) e inicia sua trajetória dentro do tribunal. O registro é realizado a partir da transposição dos dados, que costumam estar na primeira folha de uma petição - nome da parte autora, classe processual a que se destina e advogado representante. Registrada a petição, o sistema gera um número de protocolo que é entregue ao advogado, confirmando o recebimento. É por esse número que 
os advogados podem acompanhar, pelo menos em parte, a movimentação dos documentos entregues, pois cada deslocamento é registrado no sistema e indica uma fase de tramitação.

As petiçóes saem do atendimento com destino ao Processamento Inicial, que compóe a Secretaria Judiciária (SEJ) do STF; é aqui que ocorre uma triagem do material entregue. ${ }^{3}$ Recursos e açóes originárias (aquelas que começam diretamente no STF) se dividem dentro desse setor em salas especializadas. São verificados, nesse momento, alguns dos requisitos formais de admissão de cada tipo de petição: presença de todas as peças processuais e o prazo regular de cada classe. Nas açóes do chamado controle concentrado, como as açóes diretas de inconstitucionalidade, essa triagem é uma conferência de tudo o que foi entregue, ao contrário dos recursos, em que esse procedimento é muito mais complexo, pelo menos depois do instituto da Repercussão Geral, procedimento que agrega vários recursos numa só questão, objeto de uma única decisão.

Para a Repercussão Geral operam diversos filtros, que funcionam com base em temas numerados: cada tema corresponde a uma questáo jurídica. Por exemplo, o tema 241 identifica a controvérsia relacionada à obrigatoriedade do Exame da Ordem, e o tema 347 identifica a controvérsia relacionada ao direito à atualização monetária do vale-refeição dos servidores públicos do estado do Rio Grande do Sul. Em cada tema incidem assuntos relacionados; o tema 347 é composto dos assuntos 10.304 (auxílio-alimentação) e 10.313 (servidor público civil). Aos funcionários da seção, cabe identificar se os recursos recebidos correspondem a algum tema já decidido ou com Repercussão Geral já reconhecida, ou se inauguram um tema e devem ser remetidos aos ministros. Quem inventa os temas, a rigor, são os assessores da presidência; no entanto, como quem recebe os recursos é a SEJ, dela saem várias sugestốes de temas a serem cadastrados ou de temas em desuso que devem ser modificados.

Essa primeira análise, realizada pelos técnicos e analistas, visa separar coisas iguais e coisas diferentes. A depender da classificação de cada processo, as questôes jurídicas podem se tornar iguais, ainda que a olhos leigos como os meus se trate de coisas diferentes. Ainda assim, quando transformadas na mesma coisa, devem ter a mesma decisão. Esse parece ser o princípio da segurança jurídica. Quando processos iguais aos já decididos pelo tribunal são reconhecidos pelos analistas judiciários, ali mesmo, na seção de recursos, os processos são decididos, aplicando-se o precedente. Cada recurso "repetido" corresponde a uma decisão, tornada modelo, que é então assinada pelo presidente do tribunal. Existem vários modelos de decisão produzidos pela presidência; a aplicaçáo do modelo é supervisionada pelo chefe da seção e pelos assessores da presidência. Algumas 
vezes, os analistas identificam erros na "aplicação" dos modelos, o que evidencia que a "técnica" que identifica conexôes e semelhanças entre os recursos exige dos servidores uma compreensão da demanda que não é consensual. As questôes são, desse modo, tornadas semelhantes ou iguais a partir da intervenção, filtragem e classificação realizada pelo tribunal.

Os modelos de decisão também se aplicam a recursos fora do prazo e na falta de documentação. Quando estive na seção, observei um analista ensinando uma funcionária nova a encontrar as peças no processo. Com os autos em sua mesa, dizia ele: "está vendo aqui? (apontava para o timbre do papel que identificava o tribunal que proferiu decisão anterior; tratava-se de um recurso). Esse é o acórdão recorrido. Você marca essa peça e anota o número da página aqui" (e apontava para um formulário em cima da mesa). Saber procurar as peças identificando pelos timbres dos papéis os tipos de conteúdo de cada documento possibilita aos funcionários uma leitura estratégica dos autos, com vistas a preencher um formulário com o que consta e o que falta. O preenchimento de cada tópico do formulário indica procedimentos que devem ser acionados. É possível também identificar, nesse tipo de leitura e classificação, critérios estéticos (Riles, 2011) acionados na análise processual. Nos termos de Strathern (2006), cada tipo de documento deve seguir padrôes de inteligibilidade próprios ao seu universo. $\mathrm{Ou}$ seja, trata-se de obedecer uma gramática específica, uma forma correta de organizar as informaçóes de modo a tornar os documentos rapidamente decodificáveis pelos servidores e operadores do direito. Mais do que as dimensôes discursivas do conteúdo, seria preciso acionar as qualidades formais desses processos de produção de documentos legais.

Se no caso dos recursos (que representam a maioria dos processos que chegam ao STF) vários desses critérios de legibilidade são testados já na SEJ, impedindo a subida dos autos aos gabinetes, no caso dos processos originários, o papel da secretaria é mais restrito. Essa categoria de processos costuma ter uma trajetória mais longa, que requer procedimentos que só podem ser realizados pelos gabinetes, depois de sua autuação. O termo "autuar" significa colocar em processo, ou seja, colocar em circulação. $\mathrm{Na}$ autuação, todas as páginas da petição são carimbadas com o selo do STF e numeradas - a caneta, seguindo uma nova ordem que leva em conta os papéis de registro produzidos pelo tribunal e incluídos nos autos. Essa nova numeração deverá servir de referência em todo o processamento. $\mathrm{O}$ que pode parecer uma bobagem — a numeração das páginas — é um ato processual que determina o que está ou não nos autos, o que faz parte ou não do processo. Existem determinaçóes dos próprios ministros para acrescentar ou excluir documentos. Quando isso acontece, tudo é renumerado. 
A autuação confere ao conjunto de documentos de um processo uma pasta colorida, que identifica a classe processual daquela demanda, e uma etiqueta que classifica as pessoas de um processo. Essa primeira etiqueta não é definitiva, sendo substituída diversas vezes no decorrer do processamento, de acordo com a inserção de outras pessoas e instituiçóes nos autos. O procedimento de identificar pessoas e instituiçóes nos autos, inserindo-as em categorias distintas (arguente, arguido, interessado), implica dar a cada uma delas uma posição no processo e determina as formas como agenciam e serão agenciadas. Caso uma demanda não possa ser encaixada em uma das cores de pastas disponíveis, certamente não poderá ser julgada pelo tribunal.

$\mathrm{Na}$ plataforma virtual de autuação, o servidor estabelece também uma primeira indexação, que segue a Tabela Única de Assuntos Processuais, editada pelo Conselho Nacional de Justiça com o objetivo de padronizar o cadastro de processos e facilitar o controle estatístico do Poder Judiciário. ${ }^{4}$ Para a indexação, é necessária ao funcionário uma mínima compreensão do que se passa naquele processo, da natureza do pedido, caso contrário, a indexaçáo pode induzir a erro do processamento e a erro na decisão.

No sistema informatizado da SEJ, cada área do direito, das 16 identificadas, funciona como pastas: ao clicar em uma área, aparecem outras opçóes e, dentro delas, ainda outras, tornando a indexação cada vez mais específica. Cada área do direito identificada nos processos atrai uma legislação específica, um modo de operação. Uma das vezes em que me encontrava na seção, vi um manual para a identificação de assuntos e as classes das petiçóes, produzido pela secretaria e disponível em quase todas as mesas dos servidores. Folheando as primeiras páginas, observei recomendaçóes para essas identificaçôes. A primeira sugeria perguntas a serem respondidas pelo servidor. Com recomendaçóes sobre como responder a essas perguntas, o manual identificava em que lugar da petição estariam as respostas: do que se trata esse processo? Qual a relaçáo jurídica entre as partes? A resposta, geralmente, encontra-se no início da petição. O que se quer com esse processo? Em petiçóes bem formuladas, em regra, a resposta está ao final da petição.

Reconhecendo os assuntos e as demandas, é possível registrá-las com mais precisão. A indexação seria um primeiro frame do processo - baseio-me aqui em Bateson (1972), para quem a definiçáo de quadros (frames) determina todo um sistema de premissas para a leitura da mensagem. No nosso caso, esse sistema de premissas envolve trajetórias processuais definidas a partir das indexaçóes, desenhando e constituindo as decisóes. O que quero dizer é que a decisão começa muito antes de serem redigidos os votos dos ministros e, como vimos, pode 
terminar sem que tenha jamais passado por um gabinete. Náo se trata de afirmar que os funcionários são quem decide os processos, mas que cada procedimento carrega mais ou menos a decisão, tem mais ou menos poder decisório.

Realizados todos os procedimentos pertinentes ao processamento inicial, o processo é transferido para a Seção de Prevenção e Distribuição. Cada movimento dos autos deve ser registrado em uma guia de deslocamento recebida pelas seçóes para onde eles se destinam. Quem os recebe confere, e nesse caso a numeração das páginas é fundamental. São também registrados os atos processuais, incorporando mais documentos aos processos, mas de um tipo diferente; são, nos termos de Nadai (2013), "documentos que documentam" os procedimentos e permitem saber o que deve ser feito depois. Analisando processos judiciais, Visman (2008) já destacava essa dupla orientação da execução de um comando em um processo jurídico que, por um lado, gera um novo procedimento e, por outro, anota sua própria execução - o que evidencia que um processo contém sua própria progressão.

Antes de seguir para os gabinetes, os processos devem também ganhar um relator, por meio da distribuição eletrônica. O transporte para os gabinetes acontece algumas vezes por dia em carrinhos com pastas coloridas amarradas; estas são deslocadas de um setor ao outro do tribunal. Quando distribuído, o sistema gera um relatório e uma ata, disponibilizada pelo tribunal para acesso dos advogados. Ainda assim, a distribuição pode ser contestada pelas partes. Existe a possibilidade também de a distribuição ser feita pela chamada prevenção, quando processos semelhantes são encaminhados ao mesmo relator. Os critérios que fazem conexões entre os processos costumam ser diferentes do ponto de vista dos advogados e dos servidores da distribuição; desse modo, existe disputa sobre a relatoria. A partir da distribuição, as questôes procedimentais de um processo se tornam discutíveis, tendo em vista que o relator de um caso deverá guiar os votos de todo o colegiado. A escolha do ministro é importante, ou até determinante, para o resultado.

Ao chegar aos gabinetes, os processos são recebidos por um funcionário, que também deve assinar uma guia de deslocamento, permitindo o registro no sistema, o eSTF-gabinete, ou E-GAB, como é mais conhecido. Esses registros de localização são disponibilizados via internet aos interessados no processo, mas dependem da liberação de visualização, que é feita pela SEJ com a autorizaçáo dos ministros. Conforme constatei em entrevistas, o maior pesadelo de um funcionário do tribunal, seja dos gabinetes, seja da secretaria, é perder um processo. Para minimizar tal risco, existem várias ferramentas, das mais rudimentares às mais refinadas, que auxiliam os servidores a encontrar um processo em meio a centenas de pastas da mesma cor colocadas nas estantes e 
espalhadas pelo chão das salas. Cada movimento dos autos, que pode ser da mesa para a estante, é anotado e assinado. Quando os autos saem das seçóes, os funcionários identificam para onde ele deve ser deslocado, separam os volumes, preparam a guia de deslocamento, registram no programa, enviam os processos e aguardam o comprovante da entrega, para novamente registrar no sistema onde ele está. Os sistemas de controle de movimentação interna aos gabinetes estão em pequenas fichas que são temporariamente anexadas aos autos, como também por meio do sistema informatizado. Esses procedimentos de localização permitem rastrear quais funcionários estáo com determinado processo e em que estágio do processamento ele se encontra.

Ao adentrar o gabinete, o processo deve seguir a linha de produção das decisóes, passando por diversos funcionários - ou conjuntos de funcionários de estamentos diferentes, para que sejam realizados todos os atos administrativos necessários. Cada gabinete cria uma série de fluxogramas de processamento que devem ser cumpridos pelos servidores antes que os autos cheguem ao ministro. ${ }^{5}$

O primeiro procedimento é a marcação das peças processuais. Com post-its amarelos ou pequenos papéis cortados, os servidores identificam cada parte dos autos, ressaltando a urgência dos encaminhamentos. A primeira questão que deve ser identificada pelo funcionário, em processos originários, são os responsáveis pela ação. Grande parte das açôes recebidas pelo tribunal estanca já nesse primeiro momento, por falta de capacidade postulatória do arguente e legitimidade para usar o instrumento. Consta na própria Constituição quem pode acionar o STF para determinados processos. ${ }^{6}$

O passo seguinte é extrair dos documentos entregues o objeto jurídico em debate e os fundamentos legais do pedido. Esse objeto ou questáo jurídica deve ser mapeado a partir da legislação a que se refere, dos precedentes que aparecem e de alguns elementos da narração dos acontecimentos. A semelhança entre o que será decidido pelo tribunal e o que a demanda apresenta depende da capacidade do advogado de formular a questão com "clareza" e "objetividade". Durante o trabalho de campo, acompanhei algumas dessas primeiras análises das petiçóes iniciais, e inúmeras vezes ouvi os técnicos judiciários ressaltarem a dificuldade em compreender as demandas formuladas. De modo geral, os analistas judiciários reclamavam da falta de documentos fundamentais ou do excesso, da forma confusa como eram apresentadas as demandas e da imprecisão na utilização dos precedentes. Quando uma formulação é avaliada como incompreensível ou quando a ela faltam documentos importantes, o gabinete nega seguimento ao processo. Ao acompanhar algumas sessóes de julgamento, é possível notar a dificuldade dos ministros em chegar a um consenso sobre a pretensão dos processos. 
Todavia, questôes importantes ou relevantes nos termos locais quase sempre são apresentadas por advogados especializados, sendo uma parte deles bastante conhecida do tribunal por sua atuação de longa data em processos que correm no STF, ou ainda por sua reputação no universo jurídico. Desse modo, é mais difícil que cometam "erros" nas formulaçôes das petiçóes. Menciono um comentário que ouvi de um assistente do plenário durante um julgamento. Enquanto um advogado se preparava para subir à tribuna e realizar sua defesa, o funcionário comentava com o colega ao lado: “ihh! Essa causa já está perdida. Ele mal sabe colocar a toga". Mais tarde, durante o intervalo, perguntei ao assistente sobre o comentário, e ele me respondeu: "nós estamos acostumados a ver muitos advogados aqui, e sabemos quando eles estão preparados para um processo na corte. Não é fácil para ninguém subir naquele púlpito e falar diante dos ministros. Nem mesmo produzir teses jurídicas que podem convencer os ministros. Mas existem aqueles advogados acostumados, que sabem como proceder. Têm tanto conhecimento como qualquer um dos ministros do tribunal. Advogados bem preparados têm a barra da calça benfeita”, disse, rindo, deixando claro que se tratava de uma brincadeira. A reputaçáo dos advogados e sua expertise reconhecida conferem ao processo a garantia de qualidade. É deles que se esperam os grandes movimentos jurisprudenciais.

Não existem formulários para uma petição, e sim regras que devem ser cumpridas pelos advogados e documentos obrigatórios. Os argumentos devem ser apresentados na gramática própria do direito ou de uma área do direito, tendo em vista que, para os operadores, não existe uma coisa só que é o direito existem vários tipos de direito, várias formas de direito.

\section{Técnica e autonomia}

Como vimos, nesse primeiro momento os autos circulam entre a SEJ - e suas inúmeras seçôes - e o gabinete do ministro responsável. As rotinas dessas seçôes envolvem dezenas de microprocedimentos (Latour, 2002) operados por funcionários de diferentes setores. A maior ou menor autonomia desses procedimentos não depende exclusivamente do lugar em que se fazem as operaçôes, nem mesmo do tipo de operação que será realizada, mas do tipo de processo que se está produzindo. Nesse sentido, o trabalho dos gabinetes e da SEJ guarda semelhanças procedimentais, ainda que eles sejam vistos como lugares completamente distintos. $\mathrm{Na}$ realidade, grande parte dos analistas e técnicos que trabalham nos gabinetes desconhece os expedientes da SEJ. A relação entre esses dois setores é restrita à troca de processos, que saem dos gabinetes com 
determinado status e retornam modificados. Um dos servidores entrevistados relata a diferença entre esses "dois universos":

são dois lugares muito diferentes, dois universos que não se reconhecem. O trabalho da Secretaria Judiciária prepara e organiza todo o processo de acordo com o que diz a lei e o Regimento Interno. Cada um tem sua função nessa organização, e ninguém pode errar, porque qualquer erro compromete todo o processo. Nos gabinetes também não se pode errar, mas quando um processo chega ao gabinete, são realizadas outras operações, que são burocráticas também, mas que aparecem de outra maneira, como se não fossem. Os gabinetes são o lugar de prestígio dentro do tribunal, porque se trabalha junto com o ministro. ${ }^{7}$

O "ninguém pode errar", nem a secretaria nem o gabinete, parece indicar que a burocracia judicial não se separa do processo de tomada de decisão. $\mathrm{O}$ trabalho da SEJ, então, também atua com e sobre a decisão. Desse modo, parece evidente que a forma como se administra o processamento está implicada na forma como se decide. De certa maneira, todos os que trabalham para a decisão também a constituem. A decisão circula, então, à medida que circulam os autos.

Todo o trabalho da SEJ é considerado pelos seus funcionários como técnico no sentido de que eles "apenas aplicam" os procedimentos pertinentes a cada caso. Os funcionários também falam em maior "autonomia" no trabalho da secretaria, categoria cujo significado contextual diz respeito a certa independência em relação aos ministros, porquanto o juiz apenas dá o comando. $\mathrm{O}$ que será produzido a partir desse documento enviado faz parte da expertise dos analistas e dos técnicos da secretaria.

Técnica e autonomia aparecem também no discurso dos funcionários dos gabinetes, embora com significados distintos. Nos gabinetes, a preparaçáo do processo segue as regras determinadas por cada ministro e seus assessores. Os funcionários trabalham para o ministro e não para o tribunal. Os atos processuais da SEJ são todos registrados e fazem parte do processo. Já nos gabinetes, toda a preparação é interna, ou seja, apenas uma parte das ações desenroladas nos gabinetes acrescenta folhas ao processo. Enquanto documentos devem sair da SEJ assinados e carimbados por funcionários específicos, a única assinatura que conta nos gabinetes é a do próprio ministro. As intervençóes nos processos dos analistas e assessores dos gabinetes são realizadas como se eles fossem o ministro.

Nos gabinetes, toda a estrutura está marcada pela divisão do trabalho entre funcionários de maior ou menor confiança dos ministros, os mais próximos e os mais distantes, em um jogo de competências e experiências. Os cargos nos gabinetes são divididos entre estagiários, técnicos, analistas e assessores, cada um 
com tarefas específicas no gerenciamento e na preparação dos autos. Tais tarefas podem ser mais ou menos autônomas, mais ou menos técnicas, em oposição às funções de maior autonomia em relação à decisão.

O trabalho dos servidores nos gabinetes é espelhado no ministro. Entre as competências requisitadas estão conhecer a forma como cada juiz trabalha, como pensa, quais termos gosta ou não de usar, qual é seu estilo de texto, quem são seus doutrinadores de referência. "O ministro não usa expressôes em outras línguas; se elas existem, devem ser traduzidas. Sua Excelência não gosta também de usar 'resta claro', não sei dizer por que, mas não usamos 'resta claro'”, dizia-me um analista judiciário. Esse tipo de conhecimento permite que os funcionários antecipem muito do trabalho, por meio de uma "prefiguração" que reproduz, de modo mais ou menos fiel, as açôes dos ministros.

Essa divisão de trabalho nos gabinetes está também relacionada à produção de cada funcionário. Quanto mais um técnico ou analista produz, mais responsabilidade carrega e menos o seu trabalho será revisado por outros colegas, diminuindo assim a distância entre o que se produz e o ministro. Não me parece então produtivo falar em hierarquia como chave de leitura, uma vez que, se elas existem, não são fixas e tampouco regimentais. As diferenças entre os funcionários são criadas a partir de um conjunto de fatores, em um tipo de estética das relaçóes que envolve conhecimento, expertises e prestígio retomando parte do argumento de Souza (2012: 97) ao analisar as relaçóes entre os funcionários dos gabinetes. Diz a autora: "uma atribuição, prevista ou não em normativa, é mais que uma tarefa, é uma competência, que lhe [ao funcionário] traz prestígio e distinção dos demais funcionários". De todo modo, estando mais ou menos próximos aos ministros, o protocolo das relações deve sempre ser mantido. Ninguém está autorizado a chamar o ministro pelo nome, ainda que seja seu funcionário de confiança.

$\mathrm{Na}$ SEJ, existem também assimetrias que marcam a divisão do trabalho e são, sobretudo, funcionais e regimentais. Elas estão relacionadas aos cargos que os servidores podem ocupar - como chefes de seção, coordenadores ou secretários —, mas também aos tipos de processos que cada um pode gerenciar. Assimetria aqui, também, nem sempre é convertida em hierarquia. As primeiras divisóes de trabalho levam em conta o regime de contratação dos funcionários, como estatutários, terceirizados e estagiários. Processos potencialmente mais difíceis são destinados aos funcionários concursados, detentores de fé pública e de mais experiência no manejo dos procedimentos. As plataformas tecnológicas de registro e deslocamento dos processos também liberam recursos diferentes para cada servidor, o que permite ou restringe determinadas açóes. 


\section{Voltando ao processamento}

De modo geral, um processo não é resolvido logo que chega aos gabinetes. Existe uma fila de processos que se acumula nas estantes, aguardando sua hora de chegar à mesa de um dos funcionários. Os analistas aguardam que todos os procedimentos sejam cumpridos e que todos os documentos sejam entregues. A atuação do gabinete depende do que é produzido por atores que não estáo no tribunal. Os processos, quando remetidos aos agentes externos ao tribunal, trancam sua circulação. Ainda que existam prazos para que sejam devolvidos, eles nem sempre são cumpridos pelas partes, que algumas vezes "seguram" o processo, com vistas a também "segurar" a decisão.

Um processo no STF é feito de movimento e circulação, mas também de pausa, muitas vezes necessária para que a decisão se produza. No caso das questôes consideradas de grande "relevância", essas pausas são menos visíveis, dado que existe uma grande quantidade de informaçôes anexadas aos autos e um grande número de interessados na questão. Desse modo, o processo não para de circular.

Se o processo é o espaço da dúvida, como me disse o ministro Marco Aurélio quando o entrevistei, ${ }^{8}$ essa dúvida é produzida com o acúmulo de informaçôes, e um documento a mais pode fazer toda a diferença nos julgamentos. Conforme Latour (2009: 221), a operação do direito e os procedimentos técnicos destinam-se a sustentar uma "dúvida" pelo maior tempo possível, como garantia de que a decisão não foi precipitada, "arbitrária" ou "superficial". Enquanto as pastas dos volumes dos autos náo estiverem amassadas, riscadas, quase se desfazendo indicativos de que aquele processo passou pela máo de várias pessoas, foi revirado, visto e revisto —, o processo não estará pronto para ser julgado. $O$ processo então tem "substância", no sentido de que passou por várias etapas e por várias mãos.

Concluídos todos os procedimentos relativos à instruçáo do processo, a decisão pode ser finalizada, porquanto já vinha sendo produzida em todo o processamento. De modo geral, os votos e as decisôes começam oficialmente com as minutas elaboradas pelos analistas dos gabinetes. Os primeiros funcionários que preparam os processos realizam uma pesquisa no banco de dados do próprio gabinete, com o objetivo de encontrar conexôes entre o novo caso e decisóes semelhantes do "seu ministro", como disseram meus interlocutores. Nas palavras de um analista parceiro da pesquisa enquanto abria um processo em sua mesa,

primeiro eu marco com essas fichinhas as partes do processo, está vendo? Essas são as peças processuais. Tudo precisa estar no processo, senão pode dar problema. Estas formalidades são tão importantes quanto o conteúdo: o substabelecimento, a autenticação das cópias. Eu abro o processo marcado, dou uma lida [falava enquanto folheava os autos]. Depois venho aqui [abriu 
uma aba no computador] e verifico se já existe alguma decisão do ministro sobre a matéria. Se já existe, eu reproduzo aqui [mostra outra aba do navegador]. Mas isso é só o começo. Os analistas ainda vão verificar, corrigir e apresentar ao ministro, que pode mudar tudo, se quiser. Vou te mostrar outro processo [levantou da cadeira e se dirigiu à estante, de onde trouxe um processo]. No caso aqui, o objetivo desse recurso é que o ministro analise novamente as provas; ele cai pela 279.' Aqui no sistema podemos ver outras decisóes que usam a 279. Esse recurso é igual a todos esses aqui. Mas é o ministro quem decide.

Os analistas repetem insistentemente a frase "mas é o ministro quem decide", tentando reafirmar que nenhuma decisão é tomada pelos funcionários. A decisão das minutas e dos procedimentos parece uma decisão não decisória, na medida em que decisão só existe quando é assinada pelos ministros e tornada acórdáo, ${ }^{10}$ dispositivo decisório, ou seja, quando assume uma forma específica - o que não quer dizer que seu conteúdo não esteja dado antes dessa assinatura; como vimos, até mesmo a indexação carrega parte da decisão.

Objetos diferentes dão sequência aos procedimentos, e outras pesquisas serão realizadas. Ao analisar a petição inicial, o servidor encarregado vai anotando palavras-chaves em um bloco de notas em cima da sua mesa. Em seguida, abre o banco de dados e digita as palavras anotadas. Cada uma dessas palavras identifica diversos processos, que também têm seus números anotados. Assim vão se formando conexóes entre os casos, que produzem conexóes entre as decisóes. Essa busca dos precedentes que podem sustentar um posicionamento tem peculiaridades. A depender da palavra-chave que se digita, ou do número processual do assunto, o sistema encontra precedentes diferentes. Ainda no acórdáo tomado como precedente, o funcionário encontra outros números de processos relacionados utilizados naquele caso anterior, que possivelmente também serão anexados à nova decisão. Um precedente atrai outros que estão no mesmo dispositivo decisório, formando o que Abreu e Souza (2013) denominaram de "rede de precedentes". Os bancos de dados acessados pelos funcionários do tribunal são os mesmos, existindo alguns específicos para determinada classe processual. No entanto, como bem demonstraram Abreu e Souza, o próprio sistema contém limitaçôes e, a depender dos critérios de busca, encontram-se casos diferentes. Conforme os autores,

o sistema de pesquisa, que tanto nós quanto as assessorias (que fazem as minutas dos votos) dos ministros utilizam tem uma abrangência limitada. Não conhecemos as limitaçóes técnicas, e estas dependem tanto dos mecanismos de busca quanto da estrutura do banco de dados. Na prática, se, por alguma razão, o assessor considerar que a pesquisa no seu sistema não é suficiente, ele recorre à sessão de pesquisa de jurisprudência, com recursos mais avançados, e, portanto, capaz de pesquisas mais sofisticadas. No entanto, nem um nem o outro processo 
de pesquisa garantem que as assessorias de diferentes ministros váo obter os mesmos precedentes, mesmo se estiverem trabalhando com casos semelhantes. A razão disso é que para conseguir os mesmos julgados seriam necessários os mesmos critérios de busca. A mudança de uma palavra ou, dependendo do software utilizado, a alteraçáo da ordem dos termos traz resultados diferentes (Abreu \& Souza, 2013: 14).

Os analistas dos gabinetes desenvolveram estratégias próprias para a busca de precedentes. É comum que o primeiro critério seja o nome do advogado da petição. Foi-me relatado que um mesmo profissional, em casos conexos, utiliza uma petição modelo; assim, é possível aos funcionários encontrar os precedentes quase exclusivos de um determinado advogado. Também a memória dos funcionários opera na busca dos precedentes. Algumas vezes, funcionários com processos em suas mesas digitavam de memória o número de outro processo que sabiam se tratar de objetos supostamente semelhantes. Existe também a pesquisa da doutrina relacionada ao caso na mesa do analista. Por vezes, a doutrina que será usada no novo caso está no processo anterior, tomado como referência.

Os recursos de software utilizados nos gabinetes facilitam todas essas produçóes na medida em que operam com padrôes de formataçáo nos quais basta os assessores inserirem as especificidades de cada ação. Cada funcionário dos gabinetes tem um tipo de acesso aos bancos de dados contidos nos programas; o acesso ilimitado é apenas do ministro, embora não seja ele que utilize as ferramentas. A rigor, são os chefes de gabinete que usam as chaves virtuais de acesso dos ministros, e estes entram no sistema apenas para assinar eletronicamente suas decisóes, ou várias de uma só vez. Mesmo com uma série de recursos tecnológicos desenvolvidos especialmente para a gerência dos processos, a tecnologia mais utilizada no tribunal sáo os post-its, colados tanto nos autos quanto na mesa e nos computadores dos funcionários; eles identificam tarefas a ser realizadas, lugares e números de processos de referência.

A partir das pesquisas, minutas de decisão são produzidas e inseridas no sistema, com uma marca d'água na página "em elaboração", e seguem para revisão antes que cheguem ao ministro. Com as minutas são produzidos relatórios que sintetizam as informaçóes e os argumentos dos autos. Os analistas selecionam ou extraem, nos termos locais, os argumentos mais importantes de cada petição, juntando-os no mesmo documento. De certa forma, ainda que possa ler grande parte do processo, um ministro trabalha a partir dos relatórios dos analistas. $\mathrm{Na}$ realidade, ninguém lê todo o processo, porque nem todos os documentos inseridos nos autos são produzidos para ser lidos; alguns deles precisam apenas constar, pois têm papel meramente formal. 
As minutas são vistas como sugestôes de voto e permitem um tipo de debate entre os assessores e analistas com o ministro por meio das revisóes. Quando os ministros analisam as minutas, por vezes, pedem correçóes, requisitam outras pesquisas ou minutas em sentido contrário àquele apresentado. A capacidade de uma minuta se tornar o voto depende de alguns fatores. O primeiro deles está nos processos repetidos, sendo as minutas um tipo de padrão de decisão, ou seja, o ministro já decidiu aquela questão. Outros casos envolvem áreas específicas de conhecimento jurídico, o que garante a alguns funcionários maior intervenção na decisão do ministro, tendo em vista que um juiz não domina todas as áreas do direito; por isso se cerca de funcionários que podem preencher essas lacunas. Existe ainda a possibilidade de o ministro mudar a posiçáo durante o julgamento; nesse caso, pode pedir que uma nova minuta seja feita rapidamente ou declarar seu voto apenas com as anotações feitas em plenário. No entanto, isso só ocorre em processos "comuns"; nos mais "difíceis", os ministros sempre levam o voto preparado.

A complexidade dos processos atrai a competência dos assessores mais próximos ao ministro e mais especializados. São esses analistas e assessores, alguns com cargos de confiança indicados diretamente pelo ministro, que vão auxiliá-lo a produzir sua decisão a partir de outras conexôes e analogias que não somente aquelas apresentadas pelos precedentes. É comum que ministros com carreira docente em universidades tragam para o gabinete seus orientandos de pós-graduação. Existem também funcionários de confiança herdados de ministros que se aposentam. A expertise procedimental desses funcionários auxilia os novos ministros a estabelecer seu movimento processual.

Passei algumas semanas dentro de um gabinete, tentando entender a dinâmica de produção dos processos, ao lado de assessores e técnicos, e sobretudo acompanhando o trabalho do chefe de gabinete. O "chefe", como era chamado, sentava-se a uma mesa um pouco escondida, atrás de uma parede, entre os técnicos que ocupavam a primeira parte da sala e os analistas que ocupavam uma parte separada da sala, ao lado do gabinete do ministro. No chão, ao redor da sua mesa, havia pilhas e mais pilhas de autos processuais. Era ele que controlava todo o fluxo do processamento. Enquanto tentava se mover, saltando as pilhas a seu redor, dizia-me, um tanto irritado, que grande parte dos casos que estava ali não deveria estar, que a "vocação" da corte não era julgar "ladrão de galinhas", e que ansiava por uma mudança que impedisse a "subida" desses processos "irrelevantes". Os casos que não deveriam estar ali ocupando o espaço e o tempo do tribunal são parecidos com os identificados por Yngvesson (1993) como garbage case. ${ }^{11}$ A reclamação relacionada aos casos que "não deveriam estar lá" é compartilhada pelos ministros 
da corte, que vez ou outra reivindicam mudanças na legislação visando restringir o acesso ao tribunal. Uma questão tida como "relevante" para o tribunal segue mais ou menos as indicaçóes apontadas por Boltanski (1990) para as denúncias públicas. Segundo o autor, as operaçóes que tornam as denúncias públicas são aquelas que permitem a passagem do singular para o geral, do individual para o coletivo. No entanto, as "pequenas" questóes podem abrir grande debates, ainda que não seja essa a expectativa.

Para gestar o mar de processos, dos mais aos menos relevantes (uma média de cem por semana), os analistas desenvolvem diversas práticas procedimentais. Caso os técnicos não estejam atentos, um processo pode entrar despercebido no gabinete e permanecer parado tempo demais, "prejudicando" o objeto do pedido, termo que me parece indicar que a vida deu conta de resolver a questão. Tentando sintetizar o funcionamento do gabinete, um dos analistas observou:

cada gabinete é um mini-Supremo. Os processos todos chegam e são recebidos e cadastrados no sistema do gabinete. Depois, cada parte é separada e marcada, para que se saiba em que página está cada uma das peças. Um analista faz as pesquisas referentes àquele processo e formula uma minuta, que é novamente conferida e corrigida para ser assinada; depois, mais uma vez, tudo é conferido para ser liberado. Parece simples, mas cada ação aqui éde grande responsabilidade, nada é feito de uma hora para a outra. Um processo leva tempo, especialmente os casos mais difíceis. O gabinete prepara tudo, mas quem decide é o ministro. ${ }^{12}$

Enquanto permanecia sentada ao lado do chefe, consegui visualizar a complexidade que envolve um processo pelo movimento das pessoas que sentavam e levantavam, carregando volumes e mais volumes de autos processuais de um lado para o outro. Traziam pilhas de papéis, que eram as decisôes impressas, assinadas pelo ministro e que deveriam entáo ser anexadas aos seus respectivos processos. Toda aquela aparente desordem era mais ou menos controlada pelo chefe de gabinete. Cada funcionário tinha uma meta de processos para "fazer" durante o dia. "Fazer processo" significa identificar o objeto jurídico, separar as peças e os argumentos, definir os parâmetros jurisprudenciais ou pelo menos parte deles, produzir relatórios e minutas e liberar os autos para outros analistas.

No final do dia, o chefe organizava os relatórios, os memoriais e as pesquisas, que seriam enviados à casa do ministro e voltariam ao gabinete no dia seguinte, para que se desse encaminhamento às decisóes. A casa dos ministros costuma ser uma extensão de seu gabinete; alguns dos ministros trabalham em seu escritório em casa nos dias em que não há sessóes de julgamento, e alguns funcionários transitam entre o tribunal e a casa dos ministros. Alguns processos também realizam esse trânsito. 
Quando não resta nada mais a ser feito pelo gabinete, o processo é liberado. Com os autos, o relatório de todo o processamento deve ser entregue aos outros ministros. A liberação não significa que o processo será prontamente julgado. Alguns demoram anos para entrar na pauta do plenário. Não cabe ao relator a decisão de quando um processo deve ser julgado, sendo a pauta prerrogativa exclusiva da presidência do tribunal.

Depois do julgamento, os autos voltam ao gabinete do relator, que deverá formular o acórdão da decisão com base nos fundamentos enunciados pelos votos dos ministros, e seguem para sessão de composição de acórdão, que deverá incluir nos autos as notas taquigráficas, transformadas em documentos e conferidas pelos ministros. O trâmite do acórdáo pode demorar anos, embora o prazo regimental seja de vinte dias. Quando não é publicado, o acórdão não se torna precedente nem pode ser citado.

\section{O direito como objeto}

Demonstrei neste artigo que as práticas procedimentais e de documentação operam na circulação dos processos a partir de critérios distintos de classificação dos casos, das qualidades formais imprescindíveis, que se tornam parte do processo decisório. O "fazer processos" inscreve determinada disputa em uma rede de referências que estão não apenas nas normas jurídicas, mas, sobretudo, na ideia de conhecimento técnico procedimental, ou seja, naquilo que se deve fazer para produzir os processos. "Apenas preencher papéis", expressão de Ferreira (2013), é condição, parte constituinte da decisão. Retomando parte do argumento de Latour (2009), o caráter legal dos enunciados produzidos no tribunal é materializado nas passagens dos textos jurídicos, dos projetos de sentença e dos relatórios que compóem a decisão. A circulação dos autos implica diversos tipos de intervençôes, que anexam aos processos documentos de diferentes qualidades e, nos termos de Visman (2008: 15), "estão na base da validade da operação jurídica".

O "fazer processo", que na SEJ implica classificar os autos e constituí-los, e nos gabinetes identificar os parâmetros para a decisão, dilui o "poder" do juiz em um universo de actantes (Latour, 1999), que compóem uma extensa rede de produção de conhecimento. $\mathrm{Na}$ realidade, como observa Nodari (2014, comunicação pessoal), essa diluição é o próprio poder dos ministros, ou pelo menos parte fundamental desse poder, que encarnam essa rede, respondem por ela, assinam, dão nome.

$\mathrm{Na}$ trajetória dos processos no STF, que inscreve uma demanda na lógica dos procedimentos, não existem pessoas com demandas ou problemas; o que existe são temas, assuntos jurídicos, modelos e precedentes que reelaboram os objetos dos 
processos, inserindo a decisão em uma racionalidade própria ao universo jurídico, ainda que não única, tampouco plenamente estabilizada. Nesse sentido, o que tramita no tribunal são questôes jurídicas e práticas de conhecimento articuladas a cada causa jurídica. $\mathrm{O}$ tribunal ou o direito náo parecem, portanto, uma estrutura de autoridade totalmente racionalizável, ou uma essência transcendente, mas, ao contrário, uma prática mais ou menos organizada pela contingência que se efetiva por meio de fluxos, pelo incessante movimento dos autos cuja centralidade dos documentos e processos de documentação os coloca em posição de ativar, mediar e manter relaçóes. Quando se "faz um processo" para "fazer uma decisão", forma e conteúdo se misturam, inexistindo uma clara distinção entre fundo e figura, assim como são misturados ou borrados os sujeitos (de direito) e os objetos (do direito). Nos termos de Riles (2004), o direito vai produzindo significado através de seus processos de objetificação até que se torne objeto, ele mesmo, quando não existe nada a ser interpretado, quando o uso se sobrepóe ao sentido.

Uma decisão tomada como objeto não diz respeito apenas a um caso que pode resolver. Sobretudo, articula técnicas, procedimentos e temporalidades, o que nos permite deixar de lado avaliaçóes restritas à sua eficácia e referencialidade de um só momento, mostrando-se sempre em processo de transformação.

Recebido em: 04/12/2015

Aprovado em: 20/11/2016

Andressa Lewandowski é doutora em antropologia social pela Universidade de Brasília, com pesquisa nas áreas de antropologia do Estado e do direito, processos burocráticos e administrativos. 


\section{Notas}

1. Este artigo é parte de minha tese doutoral, defendida em 2014 e intitulada $O$ direito em última instância: uma etnografia do Supremo Tribunal Federal. A pesquisa de campo foi realizada entre 2011 e 2013 incluindo diversos setores do STF, entre eles dois gabinetes, a Secretaria Judiciária, os julgamentos plenários e o arquivo. Além da observação, foram realizadas entrevistas com ministros e servidores, a quem agradeço a colaboração.

2. Cabe notar que as etnografias de documentos náo são uma novidade na pesquisa antropológica; ao contrário, documentos compóem desde muito os recursos de pesquisas etnográficas. A diferença fundamental evocada nos trabalhos citados está no status dos documentos, que se desloca de meio/fonte de um conteúdo específico para o próprio objeto de investigação (Lowenkron \& Ferreira, 2014). Acompanhando esse movimento analítico, o artigo tenta contribuir para o campo de antropologia do direito, já consolidado no Brasil, a partir de um olhar que, ao invés de tomar os conteúdos das decisóes e os processos discricionários do poder judiciário, em especial dos juízes, aciona a burocracia judicial como objeto analítico.

3. A SEJ é composta por várias salas (coordenações), para onde se destinam classes de processos diferentes. É possível identificar a especialidade de cada sala pela cor dos processos nas mesas e nos armários. Todas as salas parecem revestidas por estantes em que se acumulam processos. No centro estão as baias dos funcionários, rodeadas de autos processuais, carimbos, canetas e seus computadores "decorados" com post-its amarelos. Além das classes, que dividem os funcionários em setores, o interior de cada sala de trabalho é dividido pela numeração final do processo.

4. A tabela utilizada pelo STF possui modificações realizadas pelo tribunal de modo a adequá-la às suas competências exclusivas.

5. Os gabinetes são compostos pelo chefe de gabinete (com curso superior), cinco assessores (bacharéis em direito), dois assistentes judiciários (com curso superior) e servidores e funçóes comissionadas de acordo com o decidido pela corte. Dos assessores, ao menos três devem ser do quadro interno do tribunal, conforme o artigo 357 do Regimento Interno do STF.

6. Conforme a Constituição, podem acionar o STF por meio de uma ação direta apenas as seguintes pessoas e organizaçóes: presidente da República; Mesa do Senado Federal; Mesa da Câmara dos Deputados; Mesa da Assembleia Legislativa ou da Câmara Legislativa do Distrito Federal, governador de estado ou do Distrito Federal; procurador-geral da República; Conselho Federal da Ordem dos Advogados do Brasil; partido político com representação no Congresso Nacional; confederação sindical ou entidade de classe no âmbito nacional.

7. Entrevista feita em junho de 2012 no STF.

8. Entrevista realizada em junho de 2012 no STF. 
9. Súmula 279 do STF, que diz: "para simples reexame de prova não cabe recurso extraordinário. Uma súmula é uma síntese de todos os casos, parecidos, decididos da mesma maneira, colocada por meio de uma proposição direta e clara. A súmula não possui caráter cogente, servindo apenas de orientação para futuras decisōes”.

10. Acórdão é a manifestação de um órgão judicial colegiado, que externa um posicionamento argumentando sobre a aplicabilidade de determinado direito. $\mathrm{O}$ texto é composto de quatro partes: ementa, relatório, motivação (ou fundamentação) e dispositivo, que são também seus requisitos essenciais, segundo os artigos 458 e 563 do Código de Processo Civil.

11. Conforme a autora, a corte de Massachusetts recebe grandes quantidades de casos que tratam de questóes insignificantes. Ao excluir esses casos, o tribunal não apenas se protegeria de questóes "irrelevantes" como configuraria sua própria autoridade a partir de um sistema que classifica o que cabe ou não àquele tribunal.

12. Entrevista concedida em junho de 2012 no STF.

\section{Referências}

ABREU, Luiz Eduardo \& SOUZA, Larissa. 2013. "O golpe e os marinheiros: notas sobre o uso à brasileira da jurisprudência no STF”. Revista Universitas Jus, 65-75.

BARRERA, Leticia. 2008. "Files circulation and the forms of legal experts: agency and personhood in the Argentine Supreme Court". Journal of Legal Anthropology, 1(1):3-24.

2009. Performing the court: forms and practices of legal knowledge-making in Argentina. PhD dissertation, Cornell University.

BATESON, Gregory. 1972. "Style, grace, and information in primitive art". In:

Steps to an ecology of mind. Northvale, N.J.: Jason Aronson. pp. 128-152.

BOLTANSKI, Luc. 1990. L'amour et la justice comme compétences: trois essais de sociologie de l'action. Paris: Métailié.

KANT DE LIMA, Roberto. 1989. "Cultura jurídica e práticas policiais: a tradição inquisitorial”. Revista Brasileira de Ciências Sociais, 4(10):65-84.

LATOUR, Bruno. 2009. The making of law: an ethnography of the Conseil d'Etat. Paris: La Découverte; Poche.

1999. Pandora's hope: essays on the reality of science studies. Cambridge, Mass.: Harvard University Press.

LOWENKRON, Laura \& FERREIRA, Letícia. 2014. "Anthropological perspectives on documents: ethnographic dialogues on the trail of police papers". Vibrant - Virtual Brazilian Anthropology, 11(2):76-112. 
NADAI, Larissa. 2013. Descrever crimes, decifrar convençôes narrativas: uma etnografia entre documentos oficiais da Delegacia de Defesa da Mulher de Campinas em casos de estupro e atentado violento ao pudor. Dissertação de Mestrado, Universidade Estadual de Campinas.

PEIRANO, Mariza. 2009. "O paradoxo dos documentos de identidade: relato de uma experiência nos Estados Unidos”. Horizontes Antropológicos, 15(32):53-80.

POTTAGE, Alain. 2012. "The materiality of what?" Journal of Law and Society, 39(1):167-183.

RILES, Annelise. 2006. Introduction: in response. In: . (ed.). Documents: artifacts of modern knowledge. Ann Arbor: The University of Michigan Press. pp. 1-38.

. 2011. Collateral knowledge: legal reasoning in the global financial markets. Chicago and London: University of Chicago Press. . 2004. Law as object. In: Sally Merry \& Donald Brenneis (eds.). Law and empire in the Pacific: Fiji and Hawaii. Santa Fe, N.M.: School of American Research Press. pp. 187-212.

SOUZA, Larissa Maria Melo. 2012. A fábrica de argumentos: uma etnografia da construçāo da iniquidade nos casos da anistia pelo Supremo Tribunal Federal. Dissertação de Mestrado, UniCEUB.

VISMAN, Cornellia. 2008. Files: law and media technology. Stanford, CA: Stanford University Press.

YNGVESSON, Barbara. 1993. Virtuous citizens, disruptive subjects: order and complaint in a New England Court. New York: Routledge. 


\section{Resumo}

O presente artigo é parte de uma pesquisa etnográfica realizada no Supremo Tribunal Federal (STF) entre 2011 e 2013, com o objetivo de rastrear as formas de processamento do tribunal ou, nos termos locais, as formas como se "fazem processos". Nesse sentido, busco apreender a produção jurídica no STF a partir da invenção e circulaçáo dos autos processuais. $\mathrm{O}$ artigo enfatiza a produção dos documentos, os processos de documentaçáo e os procedimentos como parte fundamental das decisôes. A aposta nos fluxos do processamento permitiu perceber e descrever que a resolução das causas envolve formas de classificaçáo e rotinas procedimentais que são menos um conjunto de normas compartilhadas e, sobretudo, um conjunto de operaçóes, algumas fórmulas mais ou menos consensuais, reinventadas e redefinidas em cada ato administrativo. Desse modo, a circulação dos processos evidencia as formas de objetificação internas aos processos jurídicos e permite pensar o direito ou os direitos como prática de conhecimento efetivada na produção processual.

\section{Palavras-chave:}

do direito, Estado, documentos, burocracia.

\section{Abstract}

This article is part of an ethnographic research produced at the Brazilian Supreme Court from 2011 to 2013. The purpose was to track back the court's methods for processing or, in local terms, for "making a file". Thereby, I pursue to apprehend the legal production on the Supreme Court from the invention and distribution of the files. The article emphasizes the documents' production, the documentation process, and the procedures as an essential part of decision-making. Venturing into the processing flows has allowed me to observe and describe that the cause resolutions includes methods of classification and routine procedures that are not a group of shared rules, but rather a group of "aesthetics criteria", slightly consensual recipes reinvented and redefined in each administrative action. In that way, the files' distribution highlights the objectification method within the legal process and allows us to think law and rights as a knowledge practice.

Keywords: law anthropology, State, documents, bureaucracy. 